\title{
Antitumor Immunity Is Controlled by Tetraspanin Proteins
}

\author{
Fleur Schaper and Annemiek B. van Sprie/*
}

Department of Tumor Immunology, Radboud Institute for Molecular Life Sciences, Radboud University Medical Center, Nijmegen, Netherlands

Antitumor immunity is shaped by the different types of immune cells that are present in the tumor microenvironment (TME). In particular, environmental signals (for instance, soluble factors or cell-cell contact) transmitted through the plasma membrane determine whether immune cells are activated or inhibited. Tetraspanin proteins are emerging as central building blocks of the plasma membrane by their capacity to cluster immune receptors, enzymes, and signaling molecules into the tetraspanin web. Whereas some tetraspanins (CD81, CD151, CD9) are widely and broadly expressed, others (CD53, CD37, Tssc6) have an expression pattern restricted to hematopoietic cells. Studies using genetic mouse models have identified important immunological functions of these tetraspanins on different leukocyte subsets, and as such, may be involved in the immune response against tumors. While multiple studies have been performed with regards to deciphering the function of tetraspanins on cancer cells, the effect of tetraspanins on immune cells in the antitumor response remains understudied. In this review, we will focus on tetraspanins expressed by immune cells and discuss their potential role in antitumor immunity. New insights in tetraspanin function in the TME and possible prognostic and therapeutic roles of tetraspanins will be discussed.

Reviewed by:

Joseph Reynolds,

Rosalind Franklin University of Medicine and Science, United States

Magdalena Plebanski,

RMIT University, Australia

${ }^{*}$ Correspondence:

Annemiek B. van Spriel annemiek.vansprie/@radboudumc.nl

Specialty section: This article was submitted to Cancer Immunity and Immunotherapy, a section of the journal Frontiers in Immunology

Received: 21 March 2018 Accepted: 14 May 2018

Published: 29 May 2018

Citation: Schaper F and van Spriel AB (2018) Antitumor Immunity Is Controlled by Tetraspanin Proteins.

Front. Immunol. 9:1185. doi: 10.3389/fimmu.2018.01185

\section{INTRODUCTION}

It is now well known that the immune system plays an important role in preventing tumor formation, growth, and metastasis. This is exemplified by the increased susceptibility of immunocompromised patients to develop cancer, and by the recent success of novel cancer immunotherapies including checkpoint inhibitors, dendritic cell (DC) vaccination, and chimeric antigen receptor T cells, which demonstrate that the immune system can be harnessed against cancer.

Antitumor immunity is dependent on tumor cell uptake by antigen-presenting cells (APCs) (DCs, macrophages) that subsequently migrate to nearby lymph nodes to activate $\mathrm{T}$ and $\mathrm{B}$ cells. After clonal expansion, antigen-specific CD8 T cells can migrate toward the tumor, aiming to destroy tumor cells, a process called tumor immunosurveillance. However, this process is far from perfect as non-immunogenic variants of the tumor escape, resulting in tumor recurrence $(1,2)$. Escape from the immune system can also occur in other ways, for instance, by inducing an immunosuppressive state in the tumor microenvironment (TME) $(3,4)$. Here, tumors create a niche where they recruit different cell types to create a specific microenvironment, which favors tumor growth and metastasis (5). These cells include immune cells, which often have acquired immunosuppressive properties, such as regulatory $\mathrm{T}$ cells (Tregs), tumor-associated macrophages, and myeloid-derived suppressor cells (MDSCs) $(6,7)$ (Figure 1). Tumor-associated macrophages are very plastic cells that can adapt their phenotype in response to different tumor cell products or hypoxia (8). Alterations in cellular 


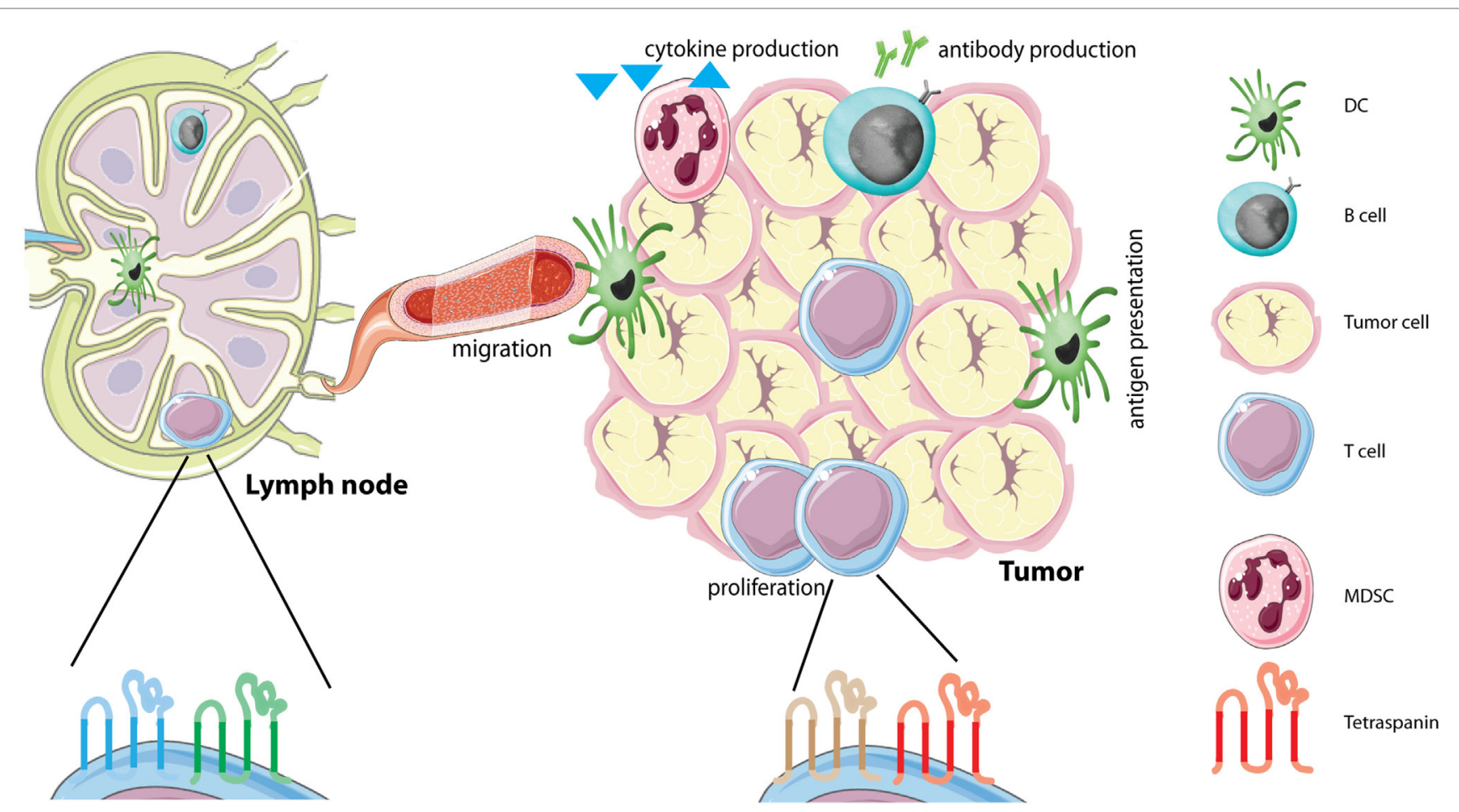

FIGURE 1 | Tetraspanins on immune cells in the tumor microenvironment (TME). The TME is comprised of several different cells, including tumor cells and different immune infiltrating cells. Immune cells in the TME produce different soluble factors, including cytokines or antibodies. Each immune cell subset contains its own distinct tetraspanin web composed of tetraspanins that can have either stimulating or inhibitory functions (see Table 1). We hypothesize that immune cells alter the composition of the tetraspanin web when they migrate from the lymph node to the tumor caused by the immunesuppressive environment of tumors. Abbreviations: DC, dendritic cell; MDSC, myeloid-derived suppressor cell.

phenotypes are often accompanied by membrane protein reorganization, as different membrane receptors will be upregulated or internalized.

Tetraspanins, or transmembrane-four superfamily proteins, are evolutionary conserved membrane organizers that regulate protein trafficking, adhesion, migration, fusion, and signaling (9-12). While many tetraspanins (CD9, CD81, CD151) are widely expressed, others are restricted to hematopoietic cells (CD37, CD53, Tssc6). Tetraspanins are not constitutively expressed on all cell types and can differ between effector fates (13-15). Tetraspanins can interact with each other and with partner proteins on the same cell whereby they form "tetraspanin-enriched microdomains" (TEMs) or "tetraspanin web” $(9,11,16)$. The overall view is that tetraspanins are modulators of signal transduction, providing organization to membrane domains through lateral interaction with their partners $(11,17-23)$, including integrins [reviewed in Ref. (24)] and immunoreceptors [CD19 (25), MHC class molecules $(17,18)]$. The immunological importance of these interactions has been demonstrated in multiple tetraspanindeficient (-/-) mice (CD37, CD53, CD81, CD82, Tssc6, CD151) that have defects in humoral and/or cellular immune responses (14, 26-29). These defects include cell migration, T cell proliferation $(27,30-32)$, antibody production $(25,33)$, and antigen presentation (14,34-36). As such, it is likely that they also control antitumor immunity. While studies have clearly demonstrated effects of tetraspanins in primary tumor progression [reviewed in
Ref. (37)] or metastasis [reviewed in Ref. (38)], detailed analyses of antitumor immunity in tetraspanin $-/-$ mice is still scarce.

Studies on human tumor cells reported associations between tetraspanin expression and tumor progression showing both reduced (CD82, CD9) and increased expression (CD151, Tspan8) in various cancer types $(12,15,37-47)$. In patients with invasive breast cancer, it was shown that CD9 on immune cells was associated with a longer disease free survival, while CD9 expression on the tumor cells showed the opposite effect (48). The relevance of CD37 in tumor suppression has been recently shown in $\mathrm{CD}_{37^{-1-}}$ mice that spontaneously develop B-cell lymphoma, and in patients with CD37-negative B-cell lymphoma that have poor survival $(45,49)$. These results are in line with studies that report tetraspanin expression to serve as a prognostic marker for cancer patients (50). In addition, these findings indicate that tetraspanins not only influence immune cell signaling but also directly protect from tumor formation. This review focuses on tetraspanins expressed on immune cells, and their possible role in antitumor responses and the TME.

\section{TETRASPANINS AND ANTIGEN PRESENTATION}

The first steps in an antitumor immune response are the uptake, processing, and presentation of tumor antigens by APCs. DCs are the most professional APCs, and infiltration of mature 
activated DCs into tumors has been associated with increased patient survival. There is also ample evidence that tumors can inhibit APCs, leading to escape from antitumor responses (51). CD53, CD81, CD82, and CD37 have been shown to associate with MHC class II complexes (17, 52-54). Recently, CD9 was reported to be involved in MHC class II trafficking in human monocyte-derived DCs (35). The functional consequences of these interactions are demonstrated by altered antigen presentation capacity of tetraspanin ${ }^{-/-}$DCs. Both CD $37^{-/-}$and CD $151^{-/-}$DCs were hyperstimulatory to CD4 and CD8 T cells, although by different underlying mechanisms. CD151 was involved in inhibiting co-stimulation, while absence of CD37 led to increased peptide presentation (34). In Tccs6xCD37 double knock-out mice, an exaggerated hyperstimulatory phenotype of DCs was observed compared to DCs of single knock-out mice (55). This study indicates complementary functions for these two tetraspanins. In addition, DCs lacking CD82 had defects in processing MHC class II (14). Tetraspanin function in crosspresentation (the presentation of extracellular antigens in the context of MHC class I) by DCs has not been investigated, but is not unlikely considering that CD53, CD81, and CD82 interact with MHC class I molecules [(17), and own unpublished data]. Moreover, DCs lacking CD82 showed defective DC-T conjugate formation (14), and CD81 was found enriched in the contact area between APCs and T cells (56), supporting a function for tetraspanins in immunological synapse formation. Finally, tetraspanins (CD63, CD9, CD81, CD37) on exosomes may influence antigen presentation possibly via transfer of MHC-peptide complexes $(57,58)$. CD63 has been reported to inhibit antigen presentation as CD63 knockdown in APCs demonstrated increased secretion of exosomes containing MHCII (59). Together, these studies show that tetraspanins control antigen presentation either at the level of MHC-T cell receptor (TCR) interactions, at the level of co-stimulation, or via exosomes, which likely has implications for antitumor responses.

\section{TETRASPANINS AND IMMUNE CELL MOTILITY}

To mount an adequate immune response, immune cells need to migrate from peripheral tissues to draining lymph nodes and to the site of the tumor. It is well known that tetraspanins interact with multiple different integrins and as such influence the migratory capacity of cells (60). In the immune system, absence of CD151 was found to decrease T cell motility, leading to reduced inflammation in a model for inflammatory bowel disease (61). Trafficking of DCs to lymph nodes has been studied in different tetraspanin-deficient mice. $\mathrm{CD} 37^{-/-}$mice challenged with two different doses of an immunogenic tumor showed defective tumor rejection compared to wild-type (WT) mice, indicating that CD37 is directly involved in antitumor immunity (62). Using irradiated tumor cells, it was shown that $\mathrm{T}$ cell responses were impaired, which was due to impaired DC migration to the draining lymph nodes (62). A different study confirmed the decreased motility of $\mathrm{CD} 37^{-1-}$ DCs (14) and neutrophils (63), and increased motility of CD $82^{-/-}$DCs (14). Interestingly, the functional effects of CD82 are opposite to those of CD37 indicating that these tetraspanins counteract each other (14). Furthermore, CD81 was reported to be important in DC migration and formation of membrane protrusions in vitro (64). The underlying molecular mechanism involved cytoskeleton rearrangements via regulation of Rac-1 and RhoA, small GTPases that regulate the actin network. CD81 was required for Rac-1 activation (65), CD82 negatively regulated RhoA, and CD37 promoted activation of Rac-1 (27). Moreover, CD37, CD81, and CD82 have all been reported to interact with integrins $(24,33$, $52,63,66)$, and although leukocytes are not dependent on integrins for migration in $3 \mathrm{D}$ environments (67), this may provide an additional mechanism for tetraspanin involvement in $2 \mathrm{D}$ migration. These studies show that tetraspanins are important in immune cell migration, thus making it likely they are also involved in leukocyte migration into the TME.

\section{T AND B CELL ACTIVATION AND PROLIFERATION}

Activation of $\mathrm{T}$ cells depends on antigen recognition presented in MHC-peptide complexes on the surface of APCs during immunological synapse formation. Recently, it was determined that CD9 and CD151 support integrin-mediated signaling at the immunological synapse in T cells (68). Accordingly, CD81 in $\mathrm{T}$ cells was involved in the organization of the immunological synapse by interacting with ICAM-1 and CD3 (69).

Antigen-presenting cell-T cell interaction and subsequent engagement of TCR and co-stimulatory molecules leads to naive $\mathrm{T}$ cell activation and proliferation (70), which can occur in the nearby lymph nodes or the TME. It is well-known that tumor-infiltrating lymphocytes can be an important prognostic factor for cancer (71). More specifically, CD8 cytotoxic T cells are associated with favorable patient outcome while Tregs are associated with decreased survival $(6,72)$. Furthermore, the positive effect of immune checkpoint inhibitors on clinical outcome of patients with melanoma or lung carcinoma shows that exhausted/ dysfunctional T cells in the TME may be reactivated by anti-PD-1 therapy $(73,74)$. Taken together, these studies underline the importance of $\mathrm{T}$ cells in anti-tumor immunity.

Different tetraspanins have been linked to $\mathrm{T}$ cell proliferation, as $\mathrm{CD}_{3} 7^{-1-}, \mathrm{CD}_{151^{-1-}}$, $\mathrm{Tssc}^{-1-}$, and $\mathrm{CD}^{-1-} \mathrm{T}$ cells were all hyperproliferative upon TCR stimulation (27, 30-32). Moreover, double CD $37^{-1-}$ Tssc $^{-1-}$ mice displayed an exaggerated hyperproliferative $\mathrm{T}$ cell response, and impaired formation of antigen-specific CD8 ${ }^{+} \mathrm{T}$ cells after infection (55). In contrast, CD151-positive human $\mathrm{T}$ cells exhibited increased proliferation compared to CD151-negative T cells (13).

Another important facet of $\mathrm{T}$ cell biology is differentiation into different sub-types. CD81 ${ }^{-/-}$mice displayed impaired Th2 responses, possibly linking tetraspanins to $\mathrm{T}$ cell differentiation (32, 75-77). These mice fail to develop Th2-dependent allergic airway hyperreactivity (77). In vitro studies revealed that altered B-T cell interactions were responsible for the deficient Th2 response (76). These studies should be further expanded to investigate different $\mathrm{T}$ cell subsets, Th1-Th2 balance, and especially T cells in the TME (such as Tregs or Th17 cells) to unravel 
tetraspanin function in $\mathrm{T}$ cell differentiation during antitumor immunity.

A recent study with $\mathrm{CD} 81^{-/-}$mice elegantly demonstrated that tumor growth and metastasis were severely impaired in CD81 ${ }^{-1-}$ mice compared to WT mice. Both Tregs and MDSCs lacking CD81 were observed to be deficient in their suppressive ability (46). This is one of the first studies investigating the effect of tetraspanins on regulatory immune cells.

B cells have a dual role in tumor immunity as they can both inhibit and stimulate tumor growth. Tumor-specific antibodies produced by B cells can opsonize tumor cells and lead to antibody-dependent cytotoxicity by natural killer (NK) cells and phagocytes. On the other hand, regulatory B cells (Bregs) secrete IL-10 and TGF $\beta$, which directly inhibit effector immune cells, thus suppressing antitumor immunity (78). Tetraspanins function in humoral immunity has been evidenced by different studies in tetraspanin-deficient mice and the first documentation of a CD81-deficient patient. CD81 is important in the trafficking of CD19, part of the co-receptor complex of the $\mathrm{B}$ cell receptor (BCR), to the surface of B cells (25). BCR signaling occurs when $\mathrm{B}$ cells encounter their antigen and is important for B cell proliferation, survival, and antibody production. Absence of CD81 led to CD19-deficiency resulting in antibody defects in mice $(32,76)$ and humans $(25)$. CD81 $1^{-/-}$mice show impaired B cell proliferation, decreased responses to Th2 stimuli, decreased antibody production (32), and impaired B cell proliferation after BCR activation (26). CD53, although not required for CD19 expression, is also important for B cell function, as we recently discovered that CD53 promoted BCR-dependent protein kinase $\mathrm{C}$ (PKC) signaling (19). Both human and murine $\mathrm{CD}^{2} 3^{-1-} \mathrm{B}$ cells have defects in translocation of PKC to the plasma membrane, consistent with an elegant study demonstrating that CD82 stabilizes PKC activation at the surface of leukemia cells (60). These findings indicate that tetraspanins can directly influence immune cell signaling. CD37 is highly expressed by B cells (79) and controls antibody production as shown in $\mathrm{CD}^{-1-}$ mice that display decreased IgG and increased IgA levels, which is a B-cell intrinsic phenotype $(29,80)$. The underlying mechanism involved CD37 regulation of $\alpha 4 \beta 1$ integrin-Akt signaling, which is required during follicular DC-B cell interactions and supports survival of IgG1-secreting cells (33). The importance of CD37 in B cell survival has been confirmed in an independent study demonstrating that the cytoplasmic domains of CD37 couple to the Pi3K-Akt survival pathway (81). Tetraspanin function in anti-tumor immunity is further supported by our unpublished findings showing increased tumor growth in $\mathrm{CD}_{53}^{-/-}$mice compared to WT mice using a syngeneic immunogenic tumor model (F. Schaper et al., in preparation), which is in accordance with the impaired anti-tumor immunity observed in $\mathrm{CD} 37^{-/-}$ mice (62).

To conclude, tetraspanins have crucial functions in both $\mathrm{T}$ and $\mathrm{B}$ cell proliferation, survival, and signaling. It is interesting that these functions are non-redundant (deficiency of one tetraspanin results in a certain phenotype) and specific (for example CD81 controls CD19, whereas CD37 controls $\alpha 4 \beta 1$ integrin on B cells). Given these specific functions of tetraspanins and their partner molecules, it stands to reason that this can result in either an antitumor or pro-tumor response mediated by immune cells in the TME.

\section{CYTOKINE PRODUCTION AND OTHER EFFECTOR FUNCTIONS}

Cytokines are a central part of cellular communication and stimulate cell migration to sides of inflammation. These cytokines can be either immunosuppressive (IL-10, TGF $\beta$, or IL-35) or proinflammatory (IL-12, $\gamma \mathrm{IFN}, \mathrm{TNF} \alpha$ ). Several studies demonstrated that tetraspanins can influence cytokine production. CD37 has been reported to inhibit IL-6 signaling upon infection (80, 82, 83), and during lymphomageneses (45). CD53 has been implicated as negative regulator of IL- $6, \mathrm{TNF} \alpha$, and IL- $1 \beta$ in a population study of house dust mite (84) and linked to TNF- $\alpha$ by genome-wide association studies (85). In line with this, CD $81^{-1-}$ DCs produced more TNF- $\alpha$ compared to WT DCs upon Listeria infection (86). Additionally, TNF- $\alpha$ production was increased by $\mathrm{CD}^{-/-}$macrophages compared to WT macrophages after stimulation with LPS (87). CD9 has also been linked to production of TGF $\beta$ and IL-10. Bregs are known to produce large amounts of IL-10 and two independent mouse studies discovered that CD9 could serve as novel phenotypic marker for Bregs $(88,89)$. Although $\mathrm{CD}^{-/-}$mice do not have aberrant $\mathrm{B}$ cell development or humoral immunity (90), Breg presence and function in $\mathrm{CD}^{-/-}$ mice has not been investigated to date.

In a small study of patients with metastatic melanoma, CD9 expression on NK cells was observed to correlate strongly with serum levels of TGF $\beta$ (91). Interestingly, CD9 was absent on NK cells in healthy controls, but upregulated after incubation with TGF $\beta(91,92)$. These CD9-positive NK cells are normally found in the maternal part of the placenta (93), where they exert immunosuppressive actions. These data indicate that suppressive factors, which are also found in the TME, can alter tetraspanin expression on immune cells, which has immunological consequences.

\section{FUTURE DIRECTIVES: TETRASPANINS ON IMMUNE CELLS IN THE TME}

Tetraspanins are emerging as important organizing proteins on immune cells that control both humoral and cellular immune responses (Table 1), by either stimulating or inhibiting immune cell function. However, more insight is needed into understanding tetraspanins on immune cells in the TME including regulatory lymphocytes, MDSCs, and tumor-associated macrophages. Recently, CD81 has been demonstrated to control MDSC and Treg function in a murine tumor model, which is the first in vivo evidence of tetraspanin function in antitumor immunity (46). This, together with the finding that $\mathrm{CD} 37^{-1-}$ mice have impaired antitumor responses (62) indicates that tetraspanins directly contribute to antitumor immunity. However, tetraspanin expression has thus far only been studied on immune cells from blood or bone marrow (79), and not yet in the TME. In this TME, both stimulating and suppressive immune cells are present, each with their own distinct tetraspanin web. We 
TABLE 1 | Key functions of individual tetraspanins on immune cell subsets.

\begin{tabular}{ll}
\hline Tetraspanin & Function on immune cells \\
\hline CD37 & - T cell proliferation, peptide MHC presentation, antibody \\
& production, IL-6 signaling by B cells \\
& + Dendritic cell (DC) migration, B cell survival \\
\hline CD53 & + B cell receptor-dependent protein kinase C signaling \\
& - IL-6, TNF $\alpha$ production \\
\hline Tssc6 & - T cell proliferation \\
\hline CD9 & - TNF- $\alpha$ production \\
& + MHC class II trafficking \\
\hline CD81 & - T cell proliferation, TNF- $\alpha$ production \\
& + DC motility, immunological synapse organization, \\
& Th2 response, antibody production \\
\hline CD82 & - DC migration \\
& + DC-T cell conjugation \\
& + Antigen presentation \\
\hline CD151 & - T cell proliferation, T cell motility, co-stimulation in DCs \\
\hline & - exosome secretion \\
\hline
\end{tabular}

-, inhibits; +, stimulates.

propose a model in which tumor cells have the ability to alter the composition of the tetraspanin web on immune cells that enter the TME from the circulation (Figure 1). Tumor environmental factors that may influence tetraspanin expression on immune cells include suppressive cytokines, low oxygen levels (hypoxia), growth factors, damage-associated molecular patterns (DAMPs) and tumor-immune cell contact. These tumor environmental factors may either increase or decrease the expression of different tetraspanins on immune cells. Plasticity of immune cells plays an important role in the TME, and it is well established that immune cells can change their phenotype by altering membrane protein expression. Since altered (increased or decreased) tetraspanin expression affects immune cell function, we hypothesize that a changed tetraspanin web supports immune cell plasticity through altered membrane protein organization. This model is supported by (1) multiple studies demonstrating that tetraspanin-deficiency affects proliferation,

\section{REFERENCES}

1. Schreiber RD. Cancer immunoediting: integrating suppression and promotion. Science (2014) 331:1565-71. doi:10.1126/science.1203486

2. Finn OJ. A believer's overview of cancer immunosurveillance and immunotherapy. J Immunol (2018) 200:385-91. doi:10.4049/jimmunol.1701302

3. Quail D, Joyce J. Microenvironmental regulation of tumor progression and metastasis. Nat Med (2013) 19:1423-37. doi:10.1038/nm.3394

4. Motz GT, Coukos G. Deciphering and reversing tumor immune suppression. Immunity (2013) 39:61-73. doi:10.1016/j.immuni.2013.07.005

5. Hanahan D, Coussens LM. Accessories to the crime: functions of cells recruited to the tumor microenvironment. Cancer Cell (2012) 21:309-22. doi:10.1016/j.ccr.2012.02.022

6. van der Woude LL, Gorris MAJ, Halilovic A, Figdor CG, de Vries IJM. Migrating into the tumor: a roadmap for T cells. Trends Cancer (2017) 3:797-808. doi:10.1016/j.trecan.2017.09.006

7. Lindau D, Gielen P, Kroesen M, Wesseling P, Adema GJ. The immunosuppressive tumour network: myeloid-derived suppressor cells, regulatory T cells and natural killer T cells. Immunology (2013) 138:105-15. doi:10.1111/imm.12036 migration, cytokine production, and antigen presentation, (2) CD9 upregulation on NK cells after TGF $\beta$ incubation leading to immunosuppressive NK cells (91), (3) regulation of TGF $\beta$ by tetraspanins $(94,95)$, and $(4)$ own unpublished observations demonstrating that human lymphocytes cultured with tumor cells change expression of multiple tetraspanins. We are only at the beginning of understanding the dynamic nature of the tetraspanin web on immune cells, and we envisage that its composition will change depending on the tumor state (elimination, equilibrium, or escape). Using multispectral imaging $(79,96)$ on resected tumor material from patients, effects on tetraspanin expression can be investigated in the future. We anticipate that targeting tetraspanins on specific immune subsets (such as CD9 on Bregs) in the TME may have therapeutic potential. Hereby, it should be taken into account that the same tetraspanin can stimulate or inhibit immune cell function, depending on the immune cell type it is expressed on. Research investigating tetraspanins as therapeutic targets in cancer is already ongoing (50), exemplified by targeting CD37 in clinical trials for B cell malignancies $(97,98)$.

Taken together, further investigation into tetraspanin function on immune cells will add to our understanding of the role that these membrane proteins play in antitumor immunity and the possibility to target the tetraspanin web on immune cells in the TME.

\section{AUTHOR CONTRIBUTIONS}

AS supervised the study and FS and AS both wrote the manuscript.

\section{ACKNOWLEDGMENTS}

AS is supported by the Netherlands Organization for Scientific Research Grant (NWO-ALW VIDI Grant 864.11.006), a Dutch Cancer Society Grant (KUN2014-6845), and the European Research Council (Consolidator Grant, 724281). We thank Dr. S. van Deventer, J. Weiden, and Dr. J. Land for critically reading the manuscript. We apologize to all authors whose work could not be cited due to space limitations.

8. Sica A, Mantovani A. Macrophage plasticity and polarization: in vivo veritas. J Clin Invest (2012) 122:787-95. doi:10.1172/JCI59643

9. Charrin S, Jouannet S, Boucheix C, Rubinstein E. Tetraspanins at a glance. J Cell Sci (2014) 127:3641-8. doi:10.1242/jcs.154906

10. Hemler ME. Tetraspanin functions and associated microdomains. Nat Rev Mol Cell Biol (2005) 6:801-11. doi:10.1038/nrm1736

11. van Deventer SJ, Dunlock V-ME, van Spriel AB. Molecular interactions shaping the tetraspanin web. Biochem Soc Trans (2017) 45:741-50. doi:10.1042/ BST20160284

12. Beckwith KA, Byrd JC, Muthusamy N. Tetraspanins as therapeutic targets in hematological malignancy: a concise review. Front Physiol (2015) 6:91. doi:10.3389/fphys.2015.00091

13. Seu L, Tidwell C, Timares L, Duverger A, Wagner FH, Goepfert PA, et al. CD151 expression is associated with a hyperproliferative $\mathrm{T}$ cell phenotype. J Immunol (2017) 199:3336-47. doi:10.4049/jimmunol.1700648

14. Jones EL, Wee JL, Demaria MC, Blakeley J, Ho PK, Vega-Ramos J, et al. Dendritic cell migration and antigen presentation are coordinated by the opposing functions of the tetraspanins CD82 and CD37. J Immunol (2016) 196:978-87. doi:10.4049/jimmunol.1500357 
15. Barrena S, Almeida J, Yunta M, López A, Fernández-Mosteirín N, Giralt M, et al. Aberrant expression of tetraspanin molecules in B-cell chronic lymphoproliferative disorders and its correlation with normal B-cell maturation. Leukemia (2005) 19:1376-83. doi:10.1038/sj.leu.2403822

16. Zuidscherwoude M, Göttfert F, Dunlock VME, Figdor CG, van den Bogaart G, van Spriel AB. The tetraspanin web revisited by super-resolution microscopy. Sci Rep (2015) 5:12201. doi:10.1038/srep12201

17. Engering A, Pieters J. Association of distinct tetraspanins with MHC class II molecules at different subcellular locations in human immature dendritic cells. Int Immunol (2001) 13:127-34. doi:10.1093/intimm/13.2.127

18. Szöllósi J, Horejsí V, Bene L, Angelisová P, Damjanovich S. Supramolecular complexes of MHC class I, MHC class II, CD20, and tetraspan molecules (CD53, CD81, and CD82) at the surface of a B cell line JY. J Immunol (1996) 157:2939-46

19. Zuidscherwoude M, Dunlock V-ME, van den Bogaart G, van Deventer SJ, van der Schaaf A, van Oostrum J, et al. Tetraspanin microdomains control localized protein kinase C signaling in B cells. Sci Signal (2017) 10:eaag2755. doi:10.1126/scisignal.aag2755

20. Yunta M, Lazo PA. Apoptosis protection and survival signal by the CD53 tetraspanin antigen. Oncogene (2003) 22:1219-24. doi:10.1038/ sj.onc. 1206183

21. Levy S, Shoham T. The tetraspanin web modulates immune-signalling complexes. Nat Rev Immunol (2005) 5:136-48. doi:10.1038/nri1548

22. Termini CM, Gillette JM. Tetraspanins function as regulators of cellular signaling. Front Cell Dev Biol (2017) 5:34. doi:10.3389/fcell.2017.00034

23. Yanez-Mo M, Barreiro O, Gordon-Alonso M, Sala-Valdes M, SanchezMadrid F. Tetraspanin-enriched microdomains: a functional unit in cell plasma membranes. Trends Cell Biol (2009) 19:434-46. doi:10.1016/j. tcb.2009.06.004

24. Berditchevski F. Complexes of tetraspanins with integrins: more than meets the eye. J Cell Sci (2001) 114:4143-51.

25. van Zelm MC, Smet J, Adams B, Mascart F, Schandené L, Janssen F, et al. CD81 gene defect in humans disrupts CD19 complex formation and leads to antibody deficiency. J Clin Invest (2010) 120:1265-74. doi:10.1172/ JCI39748

26. Miyazaki T. Normal development but differentially altered proliferative responses of lymphocytes in mice lacking CD81. EMBO J (1997) 16:4217-25. doi:10.1093/emboj/16.14.4217

27. Wright MD, Geary SM, Fitter S, Moseley GW, Lau L-M, Sheng K-C, et al. Characterization of mice lacking the tetraspanin superfamily member CD151. Mol Cell Biol (2004) 24:5978-88. doi:10.1128/MCB.24.13.59785988.2004

28. Robb L, Tarrant J, Groom J, Ibrahim M, Li R, Borobakas B, et al. Molecular characterisation of mouse and human TSSC6: evidence that TSSC6 is a genuine member of the tetraspanin superfamily and is expressed specifically in haematopoietic organs. Biochim Biophys Acta (2001) 1522:31-41. doi:10.1016/ S0167-4781(01)00306-2

29. Knobeloch KP, Wright MD, Ochsenbein AF, Liesenfeld O, Lohler J, Zinkernagel RM, et al. Targeted inactivation of the tetraspanin CD37 impairs T-cell-dependent B-cell response under suboptimal costimulatory conditions. Mol Cell Biol (2000) 20:5363-9. doi:10.1128/MCB.20.15.53635369.2000

30. van Spriel AB, Puls KL, Sofi M, Pouniotis D, Hochrein H, Orinska Z, et al. A regulatory role for CD37 in T cell proliferation. JImmunol (2004) 172:2953-61. doi:10.4049/jimmunol.172.5.2953

31. Tarrant JM, Groom J, Metcalf D, Li R, Borobokas B, Wright MD, et al. The absence of Tssc6, a member of the tetraspanin superfamily, does not affect lymphoid development but enhances in vitro T-cell proliferative responses. Mol Cell Biol (2002) 22:5006-18. doi:10.1128/MCB.22.14.5006-5018.2002

32. Maecker HT, Levy S. Normal lymphocyte development but delayed humoral immune response in CD81-null mice. JExp Med (1997) 185:1505-10. doi:10.1084/jem.185.8.1505

33. van Spriel AB, de Keijzer S, van der Schaaf A, Gartlan KH, Sofi M, Light A, et al. The tetraspanin CD37 orchestrates the $\alpha(4) \beta(1)$ integrin-Akt signaling axis and supports long-lived plasma cell survival. Sci Signal (2012) 5:ra82. doi:10.1126/scisignal.2003113

34. Sheng K-C, van Spriel AB, Gartlan KH, Sofi M, Apostolopoulos V, Ashman L, et al. Tetraspanins CD37 and CD151 differentially regulate Ag presentation and T-cell co-stimulation by DC. Eur J Immunol (2009) 39:50-5. doi:10.1002/ eji.200838798

35. Rocha-Perugini V, Martinez Del Hoyo G, Gonzalez-Granado JM, RamirezHuesca M, Zorita V, Rubinstein E, et al. CD9 regulates major histocompatibility complex class II trafficking in monocyte-derived dendritic cells. Mol Cell Biol (2017) 37: e00202-17. doi:10.1128/MCB.00202-17

36. Segura E, Villadangos JA. A modular and combinatorial view of the antigen cross-presentation pathway in dendritic cells. Traffic (2011) 12:1677-85. doi:10.1111/j.1600-0854.2011.01254.x

37. Hemler ME. Tetraspanin proteins promote multiple cancer stages. Nat Rev Cancer (2013) 14:49-60. doi:10.1038/nrc3640

38. Zöller M. Tetraspanins: push and pull in suppressing and promoting metastasis. Nat Rev Cancer (2009) 9:40-55. doi:10.1038/nrc2543

39. Takeda Y, Li Q, Kazarov AR, Epardaud M, Elpek K, Turley SJ, et al. Diminished metastasis in tetraspanin CD151-knockout mice. Blood (2012) 118:464-72. doi:10.1182/blood-2010-08-302240

40. Medrano M, Communal L, Brown KR, Iwanicki M, Normand J, Paterson J, et al. Interrogation of functional cell-surface markers identifies CD151 dependency in high-grade serous ovarian cancer. Cell Rep (2017) 18:2343-58. doi:10.1016/j.celrep.2017.02.028

41. Romanska HM, Berditchevski F. Tetraspanins in human epithelial malignancies. J Pathol (2011) 223:4-14. doi:10.1002/path.2779

42. Liu WM, Zhang XA. KAI1/CD82, a tumor metastasis suppressor. Cancer Lett (2006) 240:183-94. doi:10.1016/j.canlet.2005.08.018

43. Vences-Catalan F, Duault C, Kuo C-C, Rajapaksa R, Levy R, Levy S. CD81 as a tumor target. Biochem Soc Trans (2017) 45:531-5. doi:10.1042/ BST20160478

44. Di Giacomo V, Tian TV, Mas A, Pecoraro M, Batlle-Morera L, Noya L, et al. DeltaNp63alpha promotes adhesion of metastatic prostate cancer cells to the bone through regulation of CD82. Oncogene (2017) 36:4381-92. doi:10.1038/ onc. 2017.42

45. De Winde CM, Veenbergen S, Young KH, Xu-Monette ZY, Wang XX, Xia Y, et al. Tetraspanin CD37 protects against the development of B cell lymphoma. J Clin Invest (2016) 126:653-66. doi:10.1172/JCI81041

46. Vences-Catalán F, Rajapaksa R, Srivastava MK, Marabelle A, Kuo CC, Levy R, et al. Tetraspanin CD81 promotes tumor growth and metastasis by modulating the functions of T regulatory and myeloid-derived suppressor cells. Cancer Res (2015) 75:4517-26. doi:10.1158/0008-5472.CAN-15-1021

47. Veenbergen $S$, van Spriel AB. Tetraspanins in the immune response against cancer. Immunol Lett (2011) 138:129-36. doi:10.1016/j.imlet.2011. 03.010

48. Kwon HJ, Choi JE, Kang SH, Son Y, Bae YK. Prognostic significance of CD9 expression differs between tumour cells and stromal immune cells, and depends on the molecular subtype of the invasive breast carcinoma. Histopathology (2017) 70:1155-65. doi:10.1111/his.13184

49. Xu-Monette ZY, Li L, Byrd JC, Jabbar KJ, Manyam GC, Maria de Winde C, et al. Assessment of CD37 B-cell antigen and cell of origin significantly improves risk prediction in diffuse large B-cell lymphoma. Blood (2016) 128:3083-100. doi:10.1182/blood-2016-05-715094

50. Hemler ME. Targeting of tetraspanin proteins - potential benefits and strategies. Nat Rev Drug Discov (2008) 7:747-58. doi:10.1038/nrd2659

51. Ma Y, Shurin GV, Peiyuan Z, Shurin MR. Dendritic cells in the cancer microenvironment. J Cancer (2013) 4:36-44. doi:10.7150/jca.5046

52. Rubinstein E, Le Naour F, Lagaudriere-Gesbert C, Billard M, Conjeaud H, Boucheix C. CD9, CD63, CD81, and CD82 are components of a surface tetraspan network connected to HLA-DR and VLA integrins. Eur J Immunol (1996) 26:2657-65. doi:10.1002/eji.1830261117

53. Hammond C, Denzin LK, Pan M, Griffith JM, Geuze HJ, Cresswell P. The tetraspan protein CD82 is a resident of MHC class II compartments where it associates with HLA-DR, -DM, and -DO molecules. J Immunol (1998) 161:3282-91.

54. Angelisova P, Hilgert I, Horejsi V. Association of four antigens of the tetraspans family (CD37, CD53, TAPA-1, and R2/C33) with MHC class II glycoproteins. Immunogenetics (1994) 39:249-56. doi:10.1007/BF00188787

55. Gartlan KH, Belz GT, Tarrant JM, Minigo G, Katsara M, Sheng K-C, et al. A complementary role for the tetraspanins CD37 and Tssc6 in cellular immunity. J Immunol (2010) 185:3158-66. doi:10.4049/jimmunol. 0902867 
56. Mittelbrunn M, Yanez-Mo M, Sancho D, Ursa A, Sanchez-Madrid F. Cutting edge: dynamic redistribution of tetraspanin CD81 at the central zone of the immune synapse in both T lymphocytes and APC. JImmunol (2002) 169:6691-5. doi:10.4049/jimmunol.169.12.6691

57. Mittelbrunn M, Gutiérrez-Vázquez C, Villarroya-Beltri C, González S, Sánchez-Cabo F, González MÁ, et al. Unidirectional transfer of microRNAloaded exosomes from T cells to antigen-presenting cells. Nat Commun (2011) 2:282. doi:10.1038/ncomms1285

58. Andreu Z, Yáñez-Mó M. Tetraspanins in extracellular vesicle formation and function. Front Immunol (2014) 5:442. doi:10.3389/fimmu.2014.00442

59. Petersen SH, Odintsova E, Haigh TA, Rickinson AB, Taylor GS, Berditchevski F. The role of tetraspanin CD63 in antigen presentation via MHC class II. Eur J Immunol (2011) 41:2556-61. doi:10.1002/eji.201141438

60. Jiang X, Zhang J, Huang Y. Tetraspanins in cell migration. Cell Adh Migr (2015) 9:406-15. doi:10.1080/19336918.2015.1005465

61. Zelman-Toister E, Bakos E, Cohen S, Zigmond E, Shezen E, Grabovsky V, et al. CD151 regulates T-cell migration in health and inflammatory bowel disease. Inflamm Bowel Dis (2016) 22:257-67. doi:10.1097/MIB.0000000000000621

62. Gartlan KH, Wee JL, Demaria MC, Nastovska R, Chang TM, Jones EL, et al. Tetraspanin CD37 contributes to the initiation of cellular immunity by promoting dendritic cell migration. Eur J Immunol (2013) 43:1208-19. doi:10.1002/eji.201242730

63. Wee JL, Schulze KE, Jones EL, Yeung L, Cheng Q, Pereira CF, et al. Tetraspanin CD37 regulates $\beta 2$ integrin-mediated adhesion and migration in neutrophils. J Immunol (2015) 195:5770-9. doi:10.4049/jimmunol.1402414

64. Quast T, Eppler F, Semmling V, Schild C, Homsi Y, Levy S, et al. CD81 is essential for the formation of membrane protrusions and regulates Rac1-activation in adhesion-dependent immune cell migration. Blood (2011) 118:1818-27. doi:10.1182/blood-2010-12-326595

65. Tejera E, Rocha-Perugini V, Lopez-Martin S, Perez-Hernandez D, Bachir AI, Horwitz AR, et al. CD81 regulates cell migration through its association with Rac GTPase. Mol Biol Cell (2013) 24:261-73. doi:10.1091/mbc. E12-09-0642

66. Todros-Dawda I, Kveberg L, Vaage JT, Inngjerdingen M. The tetraspanin CD53 modulates responses from activating NK cell receptors, promoting LFA-1 activation and dampening NK cell effector functions. PLoS One (2014) 9:e97844. doi:10.1371/journal.pone.0097844

67. Lammermann T, Bader BL, Monkley SJ, Worbs T, Wedlich-Soldner R, Hirsch K, et al. Rapid leukocyte migration by integrin-independent flowing and squeezing. Nature (2008) 453:51-5. doi:10.1038/nature06887

68. Rocha-Perugini V, Gonzalez-Granado JM, Tejera E, Lopez-Martin S, Yanez-Mo M, Sanchez-Madrid F. Tetraspanins CD9 and CD151 at the immune synapse support T-cell integrin signaling. Eur J Immunol (2014) 44:1967-75. doi:10.1002/eji.201344235

69. Rocha-Perugini V, Zamai M, Gonzalez-Granado JM, Barreiro O, Tejera E, Yanez-Mo M, et al. CD81 controls sustained T cell activation signaling and defines the maturation stages of cognate immunological synapses. Mol Cell Biol (2013) 33:3644-58. doi:10.1128/MCB.00302-13

70. Chen L, Flies DB. Molecular mechanisms of T cell co-stimulation and coinhibition. Nat Rev Immunol (2013) 13:227-42. doi:10.1038/nri3405

71. PagesF, Galon J,Dieu-Nosjean M-C, TartourE, Sautes-Fridman C, Fridman W-H. Immune infiltration in human tumors: a prognostic factor that should not be ignored. Oncogene (2010) 29:1093-102. doi:10.1038/onc.2009.416

72. Galon J, Pagès F, Marincola FM, Thurin M, Trinchieri G, Fox BA, et al. The immune score as a new possible approach for the classification of cancer. J Transl Med (2012) 10:1. doi:10.1186/1479-5876-10-1

73. Sharma P, Allison JP. The future of immune checkpoint therapy. Science (2015) 348:56-61. doi:10.1126/science.aaa8172

74. Pardoll DM. The blockade of immune checkpoints in cancer immunotherapy. Nat Rev Cancer (2012) 12:252-64. doi:10.1038/nrc3239

75. Levy S. Function of the tetraspanin molecule CD81 in B and T cells. Immunol Res (2014) 58:179-85. doi:10.1007/s12026-014-8490-7

76. Deng J, Dekruyff RH, Freeman GJ, Umetsu DT, Levy S. Critical role of CD81 in cognate T-B cell interactions leading to Th2 responses. Int Immunol (2002) 14:513-23. doi:10.1093/intimm/14.5.513

77. Deng J, Yeung VP, Tsitoura D, DeKruyff RH, Umetsu DT, Levy S. Allergeninduced airway hyperreactivity is diminished in CD81-deficient mice. J Immunol (2000) 165:5054-61. doi:10.4049/jimmunol.165.9.5054
78. Yuen GJ, Demissie E, Pillai S. B lymphocytes and cancer: a love-hate relationship. Trends Cancer (2016) 2:747-57. doi:10.1016/j.trecan.2016.10.010

79. de Winde CM, Zuidscherwoude M, Vasaturo A, van der Schaaf A, Figdor CG, van Spriel AB. Multispectral imaging reveals the tissue distribution of tetraspanins in human lymphoid organs. Histochem Cell Biol (2015) 144:133-46. doi:10.1007/s00418-015-1326-2

80. van Spriel AB, Sofi M, Gartlan KH, van der Schaaf A, Verschueren I, Torensma $\mathrm{R}$, et al. The tetraspanin protein $\mathrm{CD} 37$ regulates IgA responses and anti-fungal immunity. PLoS Pathog (2009) 5:e1000338. doi:10.1371/ journal.ppat.1000338

81. Lapalombella R, Yeh YY, Wang L, Ramanunni A, Rafiq S, Jha S, et al. Tetraspanin CD37 directly mediates transduction of survival and apoptotic signals. Cancer Cell (2012) 21:694-708. doi:10.1016/j.ccr.2012.03.040

82. Meyer-Wentrup F, Figdor CG, Ansems M, Brossart P, Wright MD, Adema GJ, et al. Dectin-1 interaction with tetraspanin CD37 inhibits IL-6 production. J Immunol (2007) 178:154-62. doi:10.4049/jimmunol.178.1.154

83. Yan J, Wu B, Huang B, Huang S, Jiang S, Lu F. Dectin-1-CD37 association regulates IL-6 expression during Toxoplasma gondii infection. Parasitol Res (2014) 113:2851-60. doi:10.1007/s00436-014-3946-1

84. Lee H, Bae S, Jang J, Choi BW, Park CS, Park JS, et al. CD53, a suppressor of inflammatory cytokine production, is associated with population asthma risk via the functional promoter polymorphism $-1560 \mathrm{C}>\mathrm{T}$. Biochim Biophys Acta (2013) 1830:3011-8. doi:10.1016/j.bbagen.2012.12.030

85. Bos SD, Lakenberg $\mathrm{N}$, van der Breggen R, Houwing-Duistermaat JJ, Kloppenburg M, de Craen AJ, et al. A genome-wide linkage scan reveals CD53 as an important regulator of innate TNF- $\alpha$ levels. Eur J Hum Genet (2010) 18:953-9. doi:10.1038/ejhg.2010.52

86. Martínez del Hoyo G, Ramírez-Huesca M, Levy S, Boucheix C, Rubinstein E, Minguito de la Escalera M, et al. CD81 controls immunity to Listeria infection through Rac-dependent inhibition of proinflammatory mediator release and activation of cytotoxic T cells. J Immunol (2015) 194:6090-101. doi:10.4049/ jimmunol.1402957

87. Suzuki M, Tachibana I, Takeda Y, He P, Minami S, Iwasaki T, et al. Tetraspanin CD9 negatively regulates lipopolysaccharide-induced macrophage activation and lung inflammation. J Immunol (2009) 182:6485-93. doi:10.4049/jimmunol. 0802797

88. Sun J, Wang J, Pefanis E, Chao J, Rothschild G, Tachibana I, et al. Transcriptomics identify CD9 as a marker of murine IL-10-competent regulatory B cells. Cell Rep (2015) 13:1110-7. doi:10.1016/j.celrep.2015.09.070

89. Matsushita T, Le Huu D, Kobayashi T, Hamaguchi Y, Hasegawa M, Naka K, et al. A novel splenic B1 regulatory cell subset suppresses allergic disease through phosphatidylinositol 3-kinase-Akt pathway activation. J Allergy Clin Immunol (2016) 138:1170-82.e9. doi:10.1016/j.jaci.2015.12.1319

90. Cariappa A, Shoham T, Liu H, Levy S, Boucheix C, Pillai S. The CD9 tetraspanin is not required for the development of peripheral B cells or for humoral immunity. J Immunol (2005) 175:2925-30. doi:10.4049/jimmunol.175.5.2925

91. Holtan SG, Creedon DJ, Thompson MA, Nevala WK, Markovic SN. Expansion of CD16-negative natural killer cells in the peripheral blood of patients with metastatic melanoma. Clin Dev Immunol (2011) 2011:316314. doi:10.1155/2011/316314

92. Keskin DB, Allan DSJ, Rybalov B, Andzelm MM, Stern JNH, Kopcow HD, et al. TGFbeta promotes conversion of CD16+ peripheral blood NK cells into CD16- NK cells with similarities to decidual NK cells. Proc Natl Acad Sci U S A (2007) 104:3378-83. doi:10.1073/pnas.0611098104

93. Koopman LA, Kopcow HD, Rybalov B, Boyson JE, Orange JS, Schatz F, et al. Human decidual natural killer cells are a unique NK cell subset with immunomodulatory Potential. J Exp Med (2003) 198:1201-12. doi:10.1084/ jem.20030305

94. Sadej R, Romanska H, Kavanagh D, Baldwin G, Takahashi T, Kalia N, et al. Tetraspanin CD151 regulates transforming growth factor beta signaling: implication in tumor metastasis. Cancer Res (2010) 70:6059-70. doi:10.1158/0008-5472.CAN-09-3497

95. Wang H-X, Hemler ME. Novel impact of EWI-2, CD9, and CD81 on TGF- $\beta$ signaling in melanoma. Mol Cell Oncol (2015) 2:e1030536. doi:10.1080/2372 3556.2015.1030536

96. Gorris MAJ, Halilovic A, Rabold K, van Duffelen A, Wickramasinghe IN, Verweij D, et al. Eight-color multiplex immunohistochemistry for simultaneous detection of multiple immune checkpoint molecules within the tumor 
microenvironment. J Immunol (2018) 200:347-54. doi:10.4049/jimmunol. 1701262

97. Betrian S, Ysebaert L, Heider KH, Delord JP, Fournié JJ, Quillet-Mary A. Idelalisib improves CD37 antibody BI 836826 cytotoxicity against chemoresistant/relapse-initiating CLL cells: a rationale for combination treatment. Blood Cancer J (2016) 6:e496-496. doi:10.1038/bcj.2016.106

98. Hicks SW, Lai KC, Gavrilescu LC, Yi Y, Sikka S, Shah P, et al. The antitumor activity of IMGN529, a CD37-targeting antibody-drug conjugate, is potentiated by rituximab in non-hodgkin lymphoma models. Neoplasia (2017) 19:661-71. doi:10.1016/j.neo.2017.06.001
Conflict of Interest Statement: The authors declare that the research was conducted in the absence of any commercial or financial relationships that could be construed as a potential conflict of interest.

Copyright $\odot 2018$ Schaper and van Spriel. This is an open-access article distributed under the terms of the Creative Commons Attribution License (CC BY). The use, distribution or reproduction in other forums is permitted, provided the original author(s) and the copyright owner are credited and that the original publication in this journal is cited, in accordance with accepted academic practice. No use, distribution or reproduction is permitted which does not comply with these terms. 